\title{
Expanding Herbal Microgreen-Mushroom Permaculture Can Be an Efficient Way to Recycle Agricultural Waste While Treating and Feeding the World
}

\author{
Derek David Schramm* \\ Department of Clinical Sciences, National University of Health Sciences, USA
}

Submission: February 21, 2018; Published: March 07, 2018

*Corresponding author: Derek David Schramm, PhD., National University of Health Sciences, Department of Clinical Sciences. 6630 78th Ave N, Pinellas Park, FL 33781, Email: dschramm@nuhs.edu

\section{Opinion}

A sustainable cycle of substrate utilization is beginning to manifest with plant waste being used as mushroom substrate, and spent (used) mushroom substrate being used in place of traditional soil, for herbal microgreen growth. This approach to efficiency and conservation an example of permaculture, or the development of agricultural ecosystems intended to be sustainable and self-sufficient. One of the great limitations to using spent (used) mushroom substrate for plant growth is that it typically must undergo months of composting prior to use for plant growth.

Current work at National University of Health Sciences, in collaboration with the UPC partnership at St Petersburg College is focused on identifying opportunities for using spent mushroom substrate for plant growth, directly, with no composting.

Specifically we have had success growing Oyster mushrooms on straw and coffee grounds, followed by taking the spent Oyster mushroom substrate and immediately using it to grow plant microgreens. The value added to agricultural efficiency is exceptional since neither the time of composting material nor a compost facility is necessary. This approach makes permaculture practical not only for traditional growers, but for small scale urban farmers who have limited space and resources.

Urban farming is a form of farming that has seen exponential growth, producing an astonishing 15 to 20 percent of the world's food (World watch Institute). In recent years, oyster mushrooms (Pleurotusostreatus) have become one of the most cultivated mushrooms in the world, due to their ease of production, adaptability to a variety of agricultural wastes, and palatable nature. Oyster mushrooms are a high yield, fast growing crop. They are known to lower blood cholesterol levels and are a great source of nutrients including potassium, iron, protein, and if exposed to sunlight, vitamin-D2. As reported herein, spent oyster mushroom substrate was used without composting to grow Cilantro, Basil, Arugula, Catnip, and Peppermint herbs. In contrast, our method was not successful growing spinach microgreens.

\section{Methodology}

Oyster mushrooms (Pleurotusostreatus) were grown on $90 \%$ straw, $9 \%$ coffee ground waste, $0.9 \%$ wheat bran, and $0.1 \%$ limestone. After inoculation with seed spawn, substrate was placed into 6-inch (diameter) filter patch bags, and incubated in the dark for a 18 day spawn run at a temperature of seventy five degrees Fahrenheit. Mushroom pinning was initiated using a 48 hour cooling cycle at fifty degrees Fahrenheit. Fruit body development occurred in 95\% humidity, 8 h 1000 lux full spectrum LED lighting, with $\sim 6$ air exchanges/ 24-h. Depending on fruiting run, efficiency of mushroom growth varied between 130 and $150 \%$, by wet weight. Following fruiting, spent substrate lost an average of $39 \%$ dry weight.

Micro-greens are a tiny form of young edible greens produced from vegetable, herb or other plants. They range in size from $1^{\prime \prime}$ to 2" long, including the stem and leaves. A MicroGreen has a single central stem which has been cut just above the soil line during harvesting. It has two fully developed cotyledon leaves and usually one pair of very small, partially developed true leaves. These nutrient rich plants can be traditional herbs like Basil or traditional food plants like spinach.

For microgreen preparation the spent mushroom substrate was pressure cooked for 2-h at 10 PSI prior to being used. Microgreen development of Arugula, Basil, Catnip, Cilantro, 
Peppermint and Spinach was compared among 3 soil-types. First, $100 \%$ potting soil was used, with plant growth in this media set as $100 \%$ for growth efficiency comparisons. Second, the plant cultivars were grown in $100 \%$ spent oyster mushroom substrate, with no potting soil. Third, plant cultivars were grown in spent oyster mushroom substrate, with $2 \mathrm{~mm}$ potting soil placed over the plant seeds. Prior to planting, seeds were soaked for 36 hours in deionized water. Following planting at a seed density of 20-30 seeds per square inch, plants grew in $75 \%$ humidity with $12 \mathrm{~h} /$ day, 1000 lux full spectrum LED lighting.

When grown in $100 \%$ spent oyster mushroom substrate layered with $2 \mathrm{~mm}$ potting soil on top, 96-97\% growth efficiency was achieved with Arugula, Basil, Catnip, Cilantro, and Peppermint. Yield was not significantly different from yield in $100 \%$ potting soil. When grown in $100 \%$ spent oyster mushroom substrate alone, without $2 \mathrm{~mm}$ of potting soil on top, growth efficiency was sixty-seven percent for Arugula, eighty one percent for Basil, seventy two percent for Catnip, eighty four percent for Cilantro, and seventy eight percent for peppermint. In conclusion, spent oyster-mushroom substrate can serve as an efficient substrate when combined with a $2 \mathrm{~mm}$ layer of topsoil, allowing mushroom waste to substitute for the majority of the potting soil traditionally used for microgreen use. This method did not work for spinach microgreen growth.

By combining mushroom and herbal microgreen propagation, agricultural waste is eliminated and conservation achieved. Although unsuccessful with spinach, high yield was achieved with Cilantro, Basil, Arugula, Catnip, and Peppermint, showing that this ecologically friendly approach to resource conservation warrents further examination and has particular value in spacechallenged environments like urban farming. 